\title{
МАССИВНАЯ ТЕКСТУРА ГОРНОЙ ПОРОДЫ: ГРАНИТ МАССИВА АКЖАЙЛЯУ, КАЗАХСТАН
}

Войтеховский Ю.Л. ${ }^{1,2}$, Захарова А.А. ${ }^{1}$

${ }^{1}$ Санкт-Петербургский Горный университет, г. Санкт-Петербург, voytekhovskiy_yul@pers.spmi.ru

${ }^{2}$ Геологический институт ФИЦ КНЦ РАН, Апатиты, woyt@geoksc.apatity.ru

Массивные текстуры весьма распространены в горных породах преимущественно магматического генезиса, означают беспорядочное пространственное распределение породообразующих минералов и противопоставляются слоистым, полосчатым, пятнистым... Правомерен вопрос: отвечает ли беспорядочное пространственное распределение идеальному перемешиванию породообразующих минералов? Для проверки гипотезы авторами взят гранит массива Акжайляу, Казахстан (рис. 1). В качестве математической модели, отвечающей идеальному перемешиванию породообразующих минералов, принято равновесие Харди-Вайнберга.

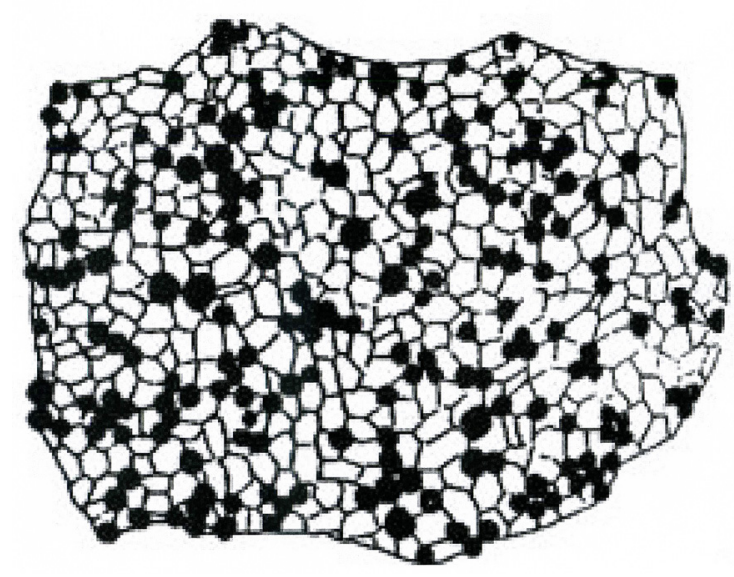

Рис. Типизированная физиография гранита B1 [1, 6]. Чёрное - квари, белое полевые шпаты, не даны слюды и амфиболь. Полированный штуф, $15 \times 10 \mathrm{~cm}$.

Английский математик Дж. Х. Харди и немецкий врач В. Вайнберг независимо получили формулу, описывающую равновесие генотипов в потомстве [6; 7, с. 126-128]. Если $p$ и $q$ - частоты (вероятности) конкурирующих генов $A$ и $B$ (в условной записи $p A+q B=1)$, то равновесные частоты генотипов $A A, A B$ (то же, что $B A$ ) и $B B$ среди потомков могут быть рассчитаны по формуле:

$$
(p A+q B)^{2}=p^{2} A A+2 p q A B+q^{2} B B=1 .
$$

Отклонения от равновесных частот указывают на генетический дрейф - результат естественного или искусственного отбора. Формула ХардиВайнберга характеризует идеальное перемешивание двух сочетаемых (сталкивающихся, конкурирующих, контактирующих...) сущностей. Она обобщается по числу слагаемых:

$$
\left(p_{1} A_{1}+\ldots+p_{n} A_{n}\right)^{2}=\sum p_{i j} A_{t} A_{j}=1, \text { где } i, j=1,2, \ldots n,
$$

и по степеням на тернарные: 


$$
\left(p_{1} A_{1}+\ldots+p_{n} A_{n}\right)^{3}=\sum p_{i j k} A_{i} A_{j} A_{k}=1, \text { где } i, j, k=1,2, \ldots n
$$

и куотернарные отношения:

$$
\left(p_{l} A_{1}+\ldots+p_{n} A_{n}\right)^{4}=\sum p_{i j k l} A_{i} A_{j} A_{k} A_{l}=1 \text {, где } i, j, k, l=1,2, \ldots n
$$

Изучение петрографических структур и текстур следовало бы выполнять в 3D. Анализ в 2D оправдывается лишь тем, что их классификация и номенклатура сформировались тоже по наблюдениям в 2D. Подсчитать статистику куотернарных отношений минеральных зёрен в горной породе сегодня технически невозможно. Стыки четырёх зёрен в петрографический шлиф не попадают. Но статистика их тернарных отношений (тройных контактов) в $n$-минеральных горных породах может быть найдена в шлифах.

Для изучаемого гранита вероятности кварца и полевого шпата (208 и 428 от их суммы): $p_{1}=0.327$ и $p_{2}=0.673$, соответственно. Расчётные вероятности тернарных контактов, отвечающие равновесию Харди-Вайнберга: $p_{111}=0.035, p_{112}=0.216, p_{122}=0.444, p_{222}=0.305$. В натуральном выражении, от общего числа 1116 тернарных контактов, это составляет: 39, 241, 496 и 340. При этом реальные числа контактов: 17, 211, 490 и 398. Расчётное значение непараметрического критерия «хи-квадрат» 26.02 значительно превышает пороговое значение 11.3 для доверительной вероятности $p=0.99$ и числа степеней свободы $d f=3$. Таким образом, для указанных параметров гипотеза о соответствии массивной текстуры изучаемого гранита равновесию Харди-Вайнберга отвергается. Причина - явно пониженные частоты $p_{111}, p_{112}$ и завышенные $p_{222}$.

Пикантность ситуации состоит в том, что даже в случае соответствия подсчитанных вероятностей теоретическим, то есть реальной текстуры равновесию Харди-Вайнберга - вывод о соответствии делается с некоторой вероятностью. Подсчитанные вероятности всегда отличаются от статистически равновесных, а равновесия Харди-Вайнберга определяют классификационные границы в многообразии статистически неравновесных ситуаций (в нашем случае - структур / текстур горных пород). Для их типизации в качестве структурных индикатрис, по аналогии с [2-4], используем ньютонову классификацию кубических кривых на плоскости [9, с. 44-53]. К сожалению, для $n>2$ математическая теория чересчур сложна и для наших целей не адаптирована [8]. Уравнение искомой кривой

$$
\sum p_{i j k} A_{i} A_{j} A_{k}=1 \text {, где } i, j, k=1,2, \ldots n
$$

для нашего случая $n=2$ (биминеральная горная порода) имеет вид (коэффициенты уравнения - подсчитанные в шлифе вероятности тернарных контактов):

$$
0.015 m_{1}^{3}+0.189 m_{1}^{2} m_{2}+0.439 m_{1} m_{2}^{2}+0.357 m_{2}^{3}=1
$$

и соответствует кривой, состоящей из двух гиперболических и одной прямолинейной ветвей (рис. 2). 


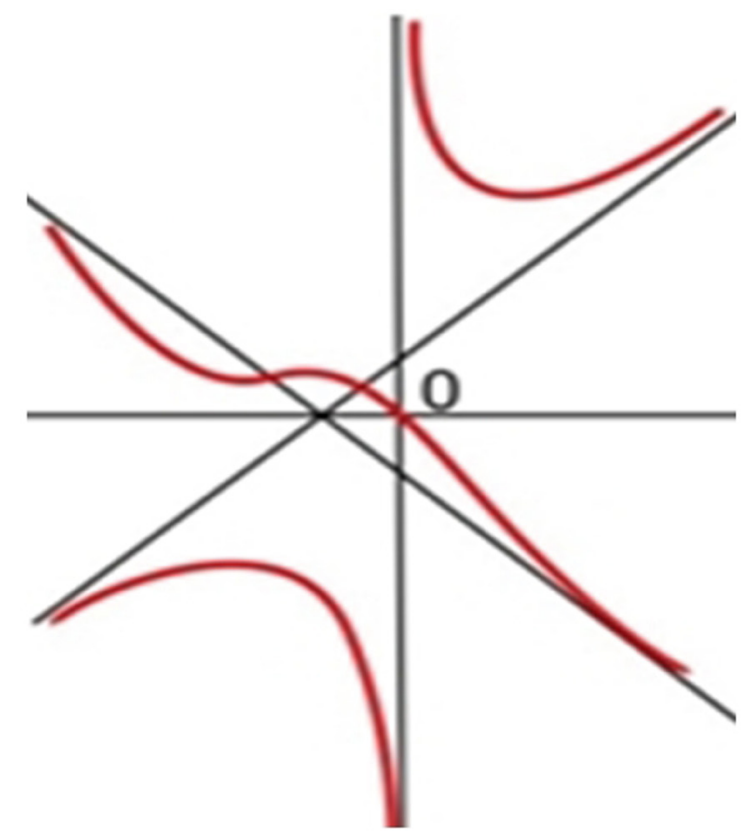

Рис. 2. Структурная индикатриса гранита массива Акжайляу (рис. 1).

Таким образом, текстуры, визуально диагностируемые как массивные, не всегда соответствуют равновесию Харди-Вайнберга, которое легко рассчитывается и может быть принято как статистически идеальное перемешивание минералов в пространстве горной породы.

Вероятности тернарных (и бинарных) межзерновых контактов, подсчитанные в петрографических шлифах, никогда не соответствуют статистически равновесным. Это ставит задачу типизации всевозможных статистически неравновесных петрографических структур. Для биминеральных горных пород (и только для них) это можно сделать на основе ньютоновой классификации плоских кубических кривых. Для любых горных пород это возможно с помощью структурных индикатрис второго порядка.

\section{Список литературы}

1. Бескин С.М., Ларин В.Н., Марин Ю.Б. Редкометалльные гранитовые формации. Л.: Недра. 1979. 280 с.

2. Войтеховский Ю.Л. К проблеме организации горных пород // Известия ВУЗов. Геология и разведка. 1991. № 10. С. 34-39.

3. Войтеховский Ю.Л. Приложение теории квадратичных форм к проблеме классификации структур полиминеральных горных пород // Известия ВУЗов. Геология и разведка. 1995. № 1. С. 32-42.

4. Войтеховский Ю.Л. Количественный анализ петрографических структур: метод структурной индикатрисы и метод вычитания акцессориев // Известия вузов. Геология и разведка. 2000. № 1. С. 50-54.

5. Добрецов Г.Л., Марин Ю.Б., Бескин С.М. и др. Принципы расчленения и картирования гранитоидных интрузий и выделения петрологометаллогенических вариантов гранитидных серий. СПб.: Изд-во ВСЕГЕИ. 2007. $80 \mathrm{c}$.

6. Коренева Л.Г. Генетика и математика // Математика и естествознание. М.: Просвещение. 1969. С. 326-383.

7. Лайтхилл Дж., Хиорнс Р.У., Холлингдейл С.Х. и др. Новые области применения математики. Мн.: Высшая школа. 1981. 496 с.

8. Манин Ю.И. Кубические формы: алгебра, геометрия, арифметика. М.: Наука. 1972. 304 с.

9. Савелов А.А. Плоские кривые: систематика, свойства, применения. Москва - Ижевск: НИЦ «Регулярная и хаотическая динамика». 2002. 294 с. 